\title{
Feasibility of Mid-Frequency Ventilation Among Infants With Respiratory Distress Syndrome
}

\author{
Ramachandra Bhat MD, John Kelleher MD, Namasivayam Ambalavanan MD, \\ Robert L Chatburn MHHS RRT-NPS FAARC, Eduardo Mireles-Cabodevila MD, and \\ Waldemar A Carlo MD
}

\begin{abstract}
BACKGROUND: Mid-frequency ventilation, a strategy of using conventional ventilators at high frequencies, may reduce lung injury but has had limited evaluation in neonates. Hence, a randomized crossover study was designed to assess the feasibility of using mid-frequency ventilation in preterm infants with respiratory distress syndrome. METHODS: Twelve preterm infants $(\geq 500 \mathrm{~g}$ and $\geq 24$ weeks gestational age) who were receiving pressure-limited conventional ventilation with frequencies $\leq \mathbf{6 0}$ breaths/min for respiratory distress syndrome were randomized to periods of mid-frequency ventilation (conventional ventilation with the fastest frequency up to $150 \mathrm{breaths} / \mathrm{min}$ that gave complete inspiration and expiration) or conventional ventilation (frequency $\leq 60 \mathrm{breaths} / \mathrm{min}$ ), each lasting $2 \mathrm{~h}$ using a crossover design. Ventilator parameters were adjusted to maintain the $\mathrm{O}_{2}$ saturation and transcutaneous $\mathrm{CO}_{2}$ at baseline. RESULTS: Mean peak inspiratory pressure $\left(15 \pm 4 \mathrm{~cm} \mathrm{H} \mathrm{H}_{2} \mathrm{O}\right.$ vs $\left.18 \pm 4 \mathrm{~cm} \mathrm{H}_{2} \mathrm{O}, P<.001\right), \Delta$ pressure $\left(9.8 \pm 3.3 \mathrm{~cm} \mathrm{H}_{2} \mathrm{O}\right.$ vs $13.5 \pm 3.9 \mathrm{~cm} \mathrm{H}_{2} \mathrm{O}$, $P<.001)$, and tidal volume $(2.6 \pm 0.4 \mathrm{~mL} / \mathrm{kg}$ vs $4.6 \pm 0.8 \mathrm{~mL} / \mathrm{kg}, P<.001)$ were lower, but mean airway pressure $\left(8.9 \pm 1.9 \mathrm{~cm} \mathrm{H}_{2} \mathrm{O}\right.$ vs $\left.8.4 \pm 1.6 \mathrm{~cm} \mathrm{H}_{2} \mathrm{O}, P=.02\right)$ and measured PEEP $\left(5.1 \pm 0.5 \mathrm{~cm} \mathrm{H} \mathrm{H}_{2} \mathrm{O}\right.$ vs $\left.4.4 \pm 0.5 \mathrm{~cm} \mathrm{H}_{2} \mathrm{O}, P<.001\right)$ were higher with mid-frequency compared with conventional ventilation. $\mathrm{F}_{\mathrm{IO} 2}$, gas exchange, and hemodynamic parameters were not affected. CONCLUSIONS: Based on this small study, mid-frequency ventilation among preterm infants with respiratory distress syndrome is feasible. Further larger and longer duration trials are necessary to validate our findings. (ClinicalTrials.gov registration NCT01242462) Key words: respiratory distress syndrome; mechanical ventilation; ventilator-induced lung injury; preterm. [Respir Care 2017;62(4):481-488. () 2017 Daedalus Enterprises]
\end{abstract}

\section{Introduction}

Antenatal corticosteroids, ${ }^{1,2}$ exogenous surfactant therapy, ${ }^{3}$ and early nasal $\mathrm{CPAP}^{4,5}$ reduce death and death or

Drs Bhat, Kelleher, Ambalavanan, and Carlo are affiliated with the University of Alabama at Birmingham, Birmingham, Alabama. Drs Chatburn and Mireles-Cabodevila are affiliated with the Cleveland Clinic, Cleveland, Ohio.

This work was supported by the Perinatal Health and Human Development Research Program of the University of Alabama at Birmingham, and Children's of Alabama Centennial Scholar Fund. Mr Chatburn and Dr Mireles-Cabodevila are the inventors named on the patent for midfrequency ventilation that is assigned to the Cleveland Clinic. Mr Chatburn has disclosed relationships with CareFusion, Covidien, Dräger, Hamilton, IngMar, Inogen, Invacare, Philips, ResMed, Neotech, and Breathe Technologies. Mr Chatburn also holds US patent 4,589,409. Mr Chatburn received royalties from Amazon.com for books on research and mechan- bronchopulmonary dysplasia in preterm infants with respiratory distress syndrome (RDS). However, the incidence of bronchopulmonary dysplasia among surviving preterm infants is increasing, ${ }^{6-8}$ in part because of increased survival of at-risk infants. Although nasal CPAP is a better ical ventilation. Dr Carlo is on the board of directors of Mednax. The
other authors have disclosed no conflicts of interest.

Dr Kelleher presented a version of this paper at the Pediatric Academic Societies 2014 annual meeting, held May 3-6, 2014, in Vancouver, Canada.

Correspondence: Waldemar A Carlo MD, Division of Neonatology, 176F Suite 9380, Women and Infants Center, University of Alabama at Birmingham, 619 20th Street South, Birmingham, AL 35233. E-mail: wcarlo@peds.uab.edu.

DOI: $10.4187 /$ respcare.05157 
choice for the initial respiratory support for RDS, 5 many preterm infants with severe respiratory failure require mechanical ventilation as a rescue therapy. ${ }^{9-11}$ However, mechanical ventilation may lead to ventilator-induced lung injury and contribute to the development of bronchopulmonary dysplasia. ${ }^{12-14}$

Reducing volutrauma and achieving patient-ventilator synchrony during mechanical ventilation are lung-protective strategies. One of the ways to reduce volutrauma and improve patient-ventilator synchrony is to increase the ventilator frequency. ${ }^{15}$ A meta-analysis of the 3 randomized, controlled trials ${ }^{16-18}$ that compared ventilation strategies with a ventilator rate of 60 breaths/min with strategies at a lower ventilator rate (usually $30-40$ breaths $/ \mathrm{min}$ ) showed a reduction in air leaks and a trend toward a decrease in mortality when faster rates were used. ${ }^{15}$ Preterm infants with RDS often breathe faster than 60 breaths $/ \mathrm{min} .{ }^{19} \mathrm{Hence}$, conventional ventilators may achieve lower tidal volumes and better synchrony at ventilator rates $>60$ breaths $/ \mathrm{min}$. Use of ventilators at rates $>60$ breaths/min (sometimes called high-frequency positive-pressure ventilation) has been reported in neonates ${ }^{20-22}$ but has not been evaluated in randomized controlled trials.

Mid-frequency ventilation is an alternative mode of ventilatory support aimed at providing the needed minute ventilation at lower tidal volumes and lower peak inspiratory pressures by operating conventional ventilators at higher than normally used ventilator rates. ${ }^{23,24}$ In the present paper, we classify mid-frequency ventilation (in its present non-commercial form) as PC-IMVs,s (this classification is very common and has many unique names). ${ }^{25}$ The mode is a form of intermittent mandatory ventilation (IMV) because spontaneous breathing is allowed, although it may not occur at high levels of ventilatory support (eg, the mode in this study was synchronized IMV pressure control on a Puritan Bennett 840 ventilator [Covidien, Mansfield, Massachusetts]). We give it the name "mid-frequency" to distinguish it from the many other forms of PC-IMVs,s and to highlight the fact that it uniquely fits in the range of ventilating frequencies between conventional rates and those used by specialized high-frequency ventilators. Although the principles of mid-frequency ventilation are similar to those of the high-frequency positive-pressure ventilation strategy, several differences suggest that midfrequency ventilation may be a better lung-protective ventilation strategy. Mid-frequency ventilation allows operation of conventional ventilators at faster rates than used by conventional ventilation (which enables better ventilatorpatient synchrony), minimizes auto-PEEP development (reducing adverse hemodynamic consequences), and decreases tidal volume and inspiratory time (gentle ventilation strategy) yet maintains alveolar minute ventilation at low delivered tidal volume (reducing adverse gas exchange consequences). Mid-frequency ventilation has been stud-

\section{QUICK LOOK}

\section{Current knowledge}

Mid-frequency ventilation is a mode of ventilation characterized by high ventilator rates and low tidal volumes aimed at reducing ventilator-induced lung injury. This is the first trial to apply the concept of mid-frequency ventilation to neonates.

\section{What this paper contributes to our knowledge}

Mid-frequency ventilation was feasible in infants with respiratory distress syndrome. Mid-frequency ventilation reduced surrogate measures of volutrauma and barotrauma without compromising gas exchange.

ied only using adult lung simulators and animal models of ARDS. ${ }^{23,24}$ Randomized crossover studies using conventional ventilators with a mid-frequency ventilation strategy have not been reported. Therefore, we conducted a trial to study the feasibility of using mid-frequency ventilation to reduce surrogate measures of lung injury in preterm infants with RDS receiving mechanical ventilation. We hypothesized that relative to a conventional ventilation strategy, a mid-frequency ventilation strategy achieves comparable gas exchange at lower $\Delta$ pressure, peak inspiratory pressure (PIP), and tidal volume.

\section{Methods}

\section{Study Design}

This was a single-center, randomized crossover, trial carried out in the neonatal ICU at the University of Alabama Hospital. Infants were randomly assigned to either conventional ventilation followed by mid-frequency ventilation (CV-MFV group) or to mid-frequency ventilation followed by conventional ventilation (MFV-CV group) based on a random sequence by using serially numbered sealed envelopes, which were opened after the informed consent. Time-cycled, demand flow (variable flow), PCIMVs,s was provided with Puritan Bennett 840 ventilators with neonatal mode software.

\section{Subjects}

Preterm infants with birthweight of $\geq 500 \mathrm{~g}$ born at or after 24 weeks completed gestation with a postnatal age $\leq 7 \mathrm{~d}$, had a clinical-radiological diagnosis of RDS, and who were receiving mechanical ventilation after surfactant treatment were eligible (Fig. 1). Infants who were already managed on conventional pressure controlled synchronized 


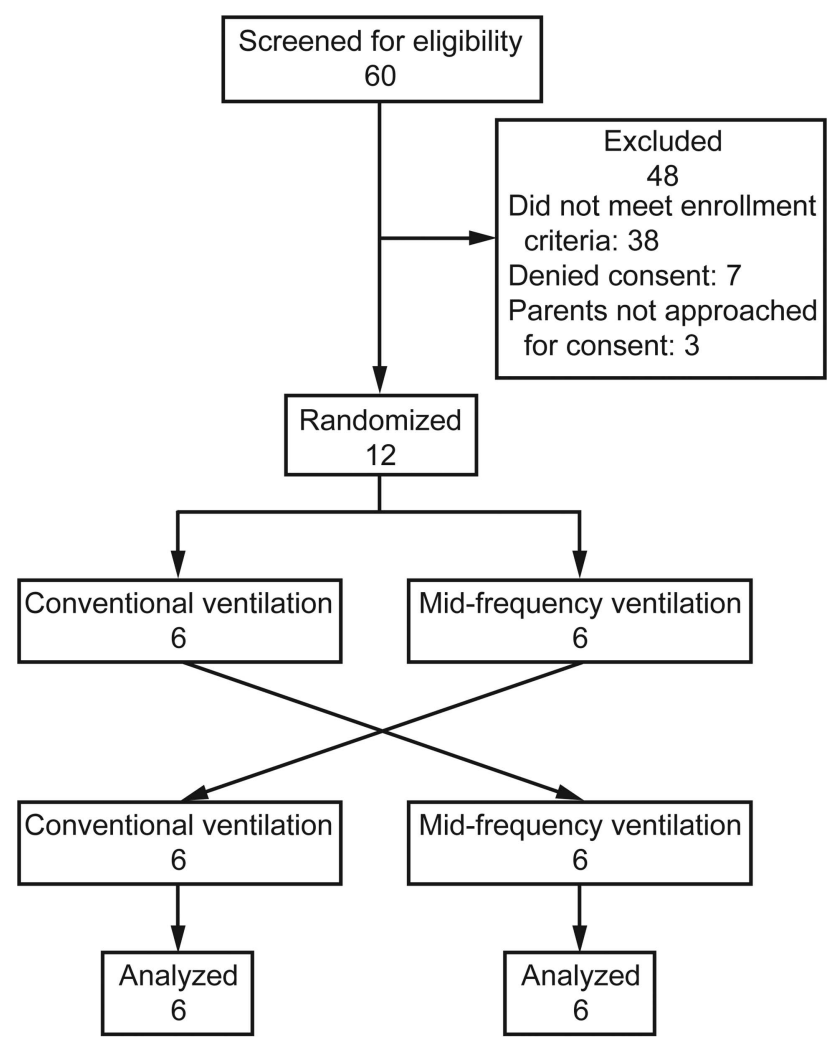

Fig. 1. Flow chart.

IMV with frequencies $>60$ breaths/min and/or receiving $\mathrm{F}_{\mathrm{IO}_{2}}<0.3$ were excluded from the study. Other exclusion criteria were blood culture-positive sepsis, life-threatening congenital anomalies, cyanotic congenital heart disease, hydrops fetalis, outborn status, and non-viability, as determined by the neonatologist, and those considered too unstable for study enrollment by the attending physician. The institutional review board of the University of Alabama at Birmingham approved the study protocol. The study was registered at ClinicalTrials.gov (NCT01242462). Informed consent was obtained from the mother or legal guardian once an infant was eligible.

Before beginning enrollment, ventilator management and other aspects of the care were as per the attending physicians' discretion. $\mathrm{S}_{\mathrm{pO}_{2}}$ and transcutaneously measured partial pressure of carbon dioxide $\left(\mathrm{P}_{\mathrm{tcCO}_{2}}\right)$ monitoring (Sentec noninvasive transcutaneous monitor) was used in all infants. $\mathrm{S}_{\mathrm{pO}_{2}}$ and $\mathrm{P}_{\mathrm{tcCO}_{2}}$ targets were set at $88-95 \%$ and $45-55 \mathrm{~mm} \mathrm{Hg}$, respectively, during the period of the study. The initial $\mathrm{S}_{\mathrm{pO}_{2}}$ and $\mathrm{P}_{\mathrm{tcCO}}$ values during the initial 30-min pretrial stabilization period were considered as baseline values for individual infants.

\section{Interventions}

Each infant was in the trial for a total of $4 \mathrm{~h}$ after random assignment to either group $\mathrm{CV}$-MFV or group

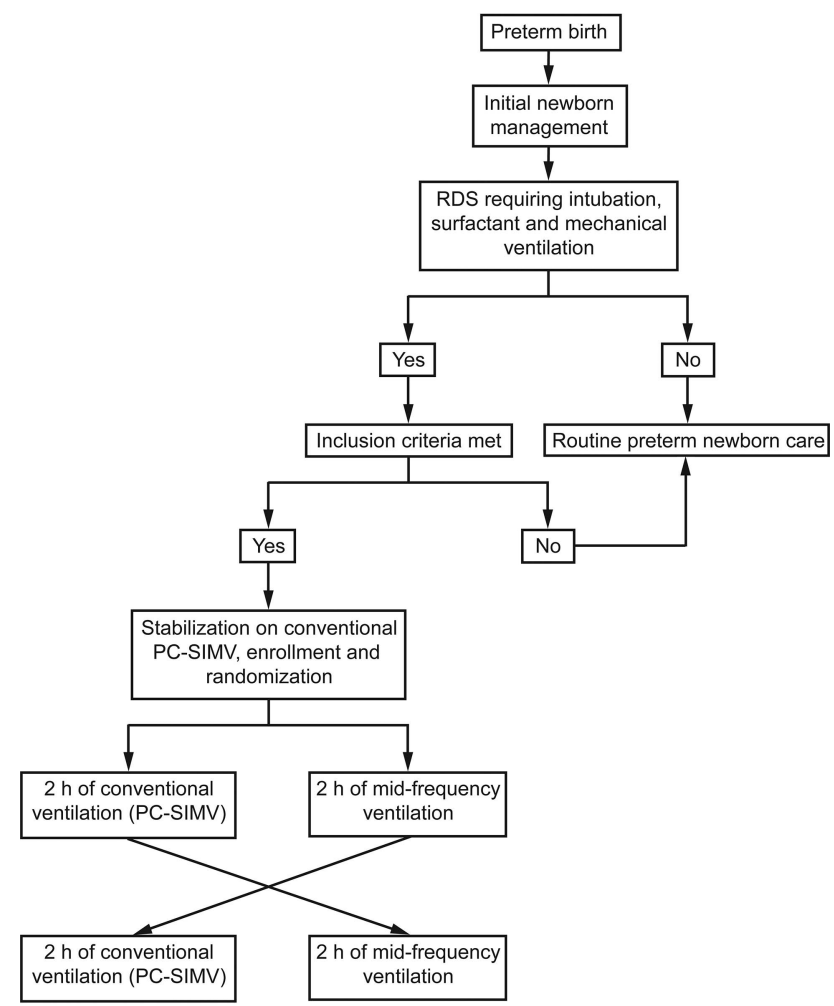

Fig. 2. Study algorithm. RDS = respiratory distress syndrome, $\mathrm{PC}-\mathrm{SIMV}=$ pressure controlled synchronized intermittent mandatory ventilation.

MFV-CV with $2 \mathrm{~h}$ in each mode of ventilation (Fig. 2). A time period at the time of crossover, wherein ventilator settings were changed from one mode to the other mode and adjusted to maintain $\mathrm{S}_{\mathrm{pO}_{2}}$ and $\mathrm{P}_{\mathrm{tcCO}_{2}}$ at baseline, was considered to be the wash-out period. Synchronized IMV pressure control was the primary mode of ventilation during both conventional ventilation and mid-frequency ventilation periods. A constant pressure support of $4 \mathrm{~cm} \mathrm{H}_{2} \mathrm{O}$ was provided throughout the study period. For Puritan Bennett 840 ventilators, inspiratory rise time is measured as percentage of flow acceleration. During conventional ventilation, we used the manufacturer's recommendation of $50 \%$ inspiratory rise time, but during mid-frequency ventilation, we used $90 \%$ (near maximum) inspiratory rise time to preserve a square pressure waveform and thus maintain tidal volume delivery for short inspiratory times..$^{23}$ Rise time was kept constant throughout the study periods.

During the period of conventional ventilation, adjustments of ventilator settings were performed to maintain $\mathrm{P}_{\mathrm{tcCO}_{2}}$ and $\mathrm{S}_{\mathrm{pO}_{2}}$ approximately at their baseline values. If $\mathrm{P}_{\mathrm{tcCO}_{2}}$ had increased from baseline, the frequency was increased to not higher than 60 breaths/min initially. If $\mathrm{P}_{\mathrm{tcCO}_{2}}$ increased, PIP was increased by $1 \mathrm{~cm}$ of $\mathrm{H}_{2} \mathrm{O}$ to maintain $\mathrm{P}_{\mathrm{tcCO}}$ approximating its baseline value. If the $\mathrm{P}_{\mathrm{tcCO}_{2}}$ had decreased from the baseline and $\mathrm{F}_{\mathrm{IO}_{2}}$ requirement was $<0.4$, then PIP was decreased by $1 \mathrm{~cm}$ of $\mathrm{H}_{2} \mathrm{O}$ so as to 
maintain $\mathrm{P}_{\mathrm{tcCO}_{2}}$ at baseline, but if the $\mathrm{F}_{\mathrm{IO}_{2}}$ requirement was $>0.4$, then the frequency was decreased to no less than 40 breaths/min. Thereafter, PIP was decreased to maintain $\mathrm{P}_{\mathrm{tcCO}_{2}}$ at its baseline value. For decreasing $\mathrm{S}_{\mathrm{pO}_{2}}$ from baseline, $\mathrm{F}_{\mathrm{IO}_{2}}$ was increased by 0.05 to a maximum of 0.7 ; thereafter, PIP was increased in a stepwise manner by $1 \mathrm{~cm} \mathrm{H}_{2} \mathrm{O}$ so as to maintain $\mathrm{S}_{\mathrm{pO}_{2}}$ between 88 and $95 \%$. Because moderate baseline PEEP $\left(4-5 \mathrm{~cm} \mathrm{H}_{2} \mathrm{O}\right)$ was already used, further increase in PEEP was avoided to prevent a negative impact on lung compliance. ${ }^{26}$ If $\mathrm{S}_{\mathrm{pO}_{2}}$ was $>95 \%, \mathrm{~F}_{\mathrm{IO}_{2}}$ was decreased by $0.03-0.05$ in a stepwise manner to a minimum of 0.4 to maintain target $\mathrm{S}_{\mathrm{pO}_{2}}$ of $88-95 \%$. If hyperoxia persisted, the mean airway pressure was reduced by decreasing PIP in a stepwise manner by $1 \mathrm{~cm} \mathrm{H}_{2} \mathrm{O}$.

During the study period of the mid-frequency ventilation strategy, the optimal frequency for each individual infant was achieved by increasing frequency to the maximum possible, between 61 and 150 breaths/min, with the shortest possible inspiratory time and expiratory time (both with a minimum of $0.2 \mathrm{~s}$ ) while achieving complete inspiratory and expiratory flows on displayed pulmonary graphics without using an inversed inspiratory-expiratory ratio. Then PIP was adjusted to maintain $\mathrm{P}_{\mathrm{tcCO}_{2}}$ at the baseline value by keeping ventilator rate constant. If $\mathrm{S}_{\mathrm{pO}_{2}}$ decreased to $<88 \%, \mathrm{~F}_{\mathrm{IO}_{2}}$ was increased initially in a stepwise manner by 0.05 each time up to a maximum of 0.7 . If $\mathrm{S}_{\mathrm{pO}_{2}}$ persisted below $88 \%$, mean airway pressure was increased by stepwise increases in PIP to maintain target level saturation. For $\mathrm{S}_{\mathrm{pO}_{2}}>95 \%, \mathrm{~F}_{\mathrm{IO}_{2}}$ was decreased in a stepwise manner to a minimum of 0.4. If $\mathrm{S}_{\mathrm{pO}_{2}}$ remained $>95 \%$, PIP was decreased by $1 \mathrm{~cm} \mathrm{H}_{2} \mathrm{O}$ to maintain $\mathrm{S}_{\mathrm{pO}_{2}}$ between 88 and $95 \%$.

\section{Outcome Variables, Data Collection, and Statistical Analyses}

The primary outcome variables in this study were the $\Delta$ pressures and tidal volumes. Secondary outcome variables for comparing the 2 modes of ventilation included set PIP, $\mathrm{F}_{\mathrm{IO}_{2}}$, mean airway pressures, frequencies, inspiratory times, measured PEEP (recorded from ventilator display), set PEEP, hemodynamic parameters (mean arterial pressure and heart rate), and gas exchange parameters $\left(\mathrm{S}_{\mathrm{pO}_{2}}\right.$ and $\left.\mathrm{P}_{\mathrm{tcCO}_{2}}\right)$. $\Delta$ pressure was calculated by subtracting measured PEEP from set PIP. A proximal airway flow sensor was not used. Exhaled tidal volumes (corrected to body temperature and pressure saturated) were recorded from ventilator screen display as estimated by the ventilator's internal flow measurement system, taking into account both ventilator circuit compliance and temperature effects. Inadvertent PEEP (at the airway opening) was estimated by deducting the set PEEP from the measured PEEP. AutoPEEP (in the lungs) was not measured because of potential interference from spontaneous breathing efforts (subjects were not paralyzed). Data on ventilator parameters, hemodynamic parameters, and gas exchange parameters were recorded every 15 min during both mid-frequency ventilation and conventional ventilation periods, and average values for individual infants during each study period were calculated. The average $\Delta$ pressure was calculated for individual infants for each study period once baseline blood gas parameters were achieved.

The sample size was based on the following assumption. During the surfactant-treated acute stage of RDS, the usual PIP requirement for a pressure-preset, time-cycled conventional ventilator operating in synchronized IMV is $\sim 10-20 \mathrm{~cm} \mathrm{H}_{2} \mathrm{O}$, and the PEEP requirement is 4-5 $\mathrm{cm} \mathrm{H}_{2} \mathrm{O} .{ }^{27}$ Hence, the $\Delta$ pressure requirement will be $\sim 6-16 \mathrm{~cm} \mathrm{H}_{2} \mathrm{O}$. Assuming the average $\Delta$ pressure to be $12 \mathrm{~cm} \mathrm{H}_{2} \mathrm{O}$ and the SD to be 3-4 $\mathrm{cm} \mathrm{H}_{2} \mathrm{O}, 12$ neonates were required to detect a $20 \%$ change in the $\Delta$ pressure when mid-frequency ventilation is used (mean difference of $2.5-3 \mathrm{~cm} \mathrm{H}_{2} \mathrm{O}$ ) by paired $t$ test with the power of the study being $80 \%$ and $\alpha$ error being .05 . The data safety monitoring board reviewed the data after the enrollment of 5 infants.

Descriptive statistics were used to compare the baseline characteristics of the study groups. Unpaired $t$ test or MannWhitney test was used to compare the baseline characteristics between the 2 groups. Ventilator parameters and hemodynamic and gas exchange variables between 2 modes of ventilation were compared by using either the paired $t$ test or Wilcoxon test based on the type of distribution. Period and carry-over effects of the first ventilation strategy over the subsequently applied ventilation strategy were evaluated by comparing sums and differences of ventilator, gas exchange, and hemodynamic parameters between the CV-MFV group and the MFV-CV group by using an unpaired $t$ test. Both primary and secondary outcomes were analyzed by 2-tailed statistical tests. Statistical significance was defined as $P<.05$.

\section{Results}

Twelve preterm infants (26 weeks, interquartile range 24-27 weeks; birthweight $792 \mathrm{~g}$, interquartile range $580-1,060 \mathrm{~g}$ ) with clinical and radiographical evidence of RDS receiving mechanical ventilation were randomized 1:1 into the study. The mothers of all infants received at least one dose of antenatal corticosteroids. Infants were enrolled at a median postnatal age of $2 \mathrm{~d}$ (interquartile range 1-2 d). Indwelling arterial lines in place in 8 infants were used to monitor the blood pressures continuously, whereas intermittent cuff blood pressure measurements were used in the other 4 infants. All of the enrolled infants successfully completed the study period of $4 \mathrm{~h}$ without adverse events. 


\section{Mid-Frequency Ventilation in Neonates with RDS}

Table 1. Baseline Ventilator and Hemodynamic Parameters of Enrolled Infants

\begin{tabular}{|c|c|c|c|}
\hline Variables & $\begin{array}{l}\text { Group } \\
\text { CV-MFV } \\
(n=6)\end{array}$ & $\begin{array}{l}\text { Group } \\
\text { MFV-CV } \\
(n=6)\end{array}$ & $P$ \\
\hline Frequency, breaths/min & $52 \pm 11$ & $55 \pm 6$ & .50 \\
\hline $\mathrm{PIP}, \mathrm{cm} \mathrm{H}_{2} \mathrm{O}$ & $18 \pm 5$ & $17 \pm 4$ & .77 \\
\hline$\Delta$ pressure, $\mathrm{cm} \mathrm{H}_{2} \mathrm{O}$ & $13.8 \pm 5.2$ & $13 \pm 4.1$ & .76 \\
\hline Inspiratory time, $\mathrm{s}$ & $0.31 \pm 0.02$ & $0.30 \pm 0.02$ & .37 \\
\hline Mean airway pressure, $\mathrm{cm} \mathrm{H}_{2} \mathrm{O}$ & $7.9 \pm 2.1$ & $8.2 \pm 1.8$ & .81 \\
\hline Tidal volume, $\mathrm{mL} / \mathrm{kg}$ & $4.4 \pm 0.5$ & $4.8 \pm 0.9$ & .33 \\
\hline $\mathrm{F}_{\mathrm{IO}_{2}}$ & $0.53 \pm 0.18$ & $0.59 \pm 0.21$ & .60 \\
\hline $\mathrm{S}_{\mathrm{pO}_{2}}, \%$ & $93 \pm 2$ & $93 \pm 2$ & .63 \\
\hline $\mathrm{P}_{\mathrm{tcCO}_{2}}, \mathrm{~mm} \mathrm{Hg}$ & $53 \pm 6$ & $54 \pm 7$ & .71 \\
\hline Oxygen saturation index & $4.8 \pm 3.2$ & $5.4 \pm 3$ & .7 \\
\hline \multicolumn{4}{|c|}{$\begin{array}{l}\text { Data are presented as mean } \pm \text { SD. } \\
\mathrm{CV}-\mathrm{MFV}=\text { conventional ventilation followed by mid-frequency ventilation } \\
\mathrm{MFV}-\mathrm{CV}=\text { mid-frequency ventilation followed by conventional ventilation } \\
\mathrm{P}_{\mathrm{tcC} 2}=\text { transcutaneously measured partial pressure of carbon dioxide }\end{array}$} \\
\hline
\end{tabular}

Baseline ventilation settings, including ventilation rate, PIP, inspiratory time, tidal volume, and $\Delta$ pressure as well as mean $\mathrm{P}_{\mathrm{tcCO}_{2}}$ and $\mathrm{F}_{\mathrm{IO}_{2}}$, did not differ between the groups (Table 1). $\Delta$ pressure decreased during mid-frequency ventilation compared with conventional ventilation $\left(9.8 \pm 3.3 \mathrm{~cm} \mathrm{H}_{2} \mathrm{O}\right.$ vs $\left.13.5 \pm 3.9 \mathrm{~cm} \mathrm{H}_{2} \mathrm{O}, P<.001\right)$. Similarly, infants required lower tidal volume during midfrequency ventilation compared with conventional ventilation $(2.6 \pm 0.4 \mathrm{~mL} / \mathrm{kg}$ vs $4.6 \pm 0.8 \mathrm{~mL} / \mathrm{kg}, P<$ $.001)$, whereas $\mathrm{F}_{\mathrm{IO}_{2}}$, gas exchange parameters $\left(\mathrm{P}_{\mathrm{tcCO}_{2}}\right.$ and $\mathrm{S}_{\mathrm{pO}_{2}}$ ), and hemodynamic parameters (blood pressure and heart rate) did not change (Table 2). As expected, the frequency achieved during mid-frequency ventilation was faster than the frequency during conventional ventilation $(134 \pm 7$ breaths $/ \mathrm{min}$ vs $56 \pm 8$ breaths $/ \mathrm{min}$, $P<.001)$. Set PIP during mid-frequency ventilation was lower than during conventional ventilation $\left(15 \pm 4 \mathrm{~cm} \mathrm{H}_{2} \mathrm{O}\right.$ vs $18 \pm 4 \mathrm{~cm} \mathrm{H}_{2} \mathrm{O}, P<.001$ ) (Table 2). The inadvertent PEEP at the airway opening generated during the midfrequency ventilation period was $0.7 \pm 0.1 \mathrm{~cm} \mathrm{H}_{2} \mathrm{O}$, and measured PEEP during mid-frequency ventilation was higher than during conventional ventilation $\left(5.1 \pm 0.5 \mathrm{~cm} \mathrm{H}_{2} \mathrm{O}\right.$ vs $\left.4.4 \pm 0.5 \mathrm{~cm} \mathrm{H}_{2} \mathrm{O}, P<.001\right)$. Mean airway pressure was also higher during the mid-frequency ventilation when compared with conventional ventilation $\left(8.9 \pm 1.9 \mathrm{~cm} \mathrm{H}_{2} \mathrm{O}\right.$ vs $8.4 \pm 1.6 \mathrm{~cm} \mathrm{H}_{2} \mathrm{O}, P=.02$ ). The mean difference was only $0.5 \mathrm{~cm} \mathrm{H}_{2} \mathrm{O}$, which might not have any clinical importance. Carryover effects in these measures were not observed. Heart rate and mean arterial pressure did not differ between mid-frequency ventilation and conventional ventilation periods. None of the infants required sedatives during the period of mid-frequency ventilation. Chest radiographs were not part of the study protocol. However, subsequently obtained routine radiographs were reviewed,
Table 2. Comparison of Ventilator, Gas Exchange, and Hemodynamic Parameters Between Mid-Frequency Ventilation and Conventional Ventilation Strategies

\begin{tabular}{|c|c|c|c|}
\hline Parameters & $\begin{array}{l}\text { Mid-Frequency } \\
\text { Ventilation }\end{array}$ & $\begin{array}{c}\text { Conventional } \\
\text { Ventilation }\end{array}$ & $P$ \\
\hline Frequency, breaths/min & $134 \pm 7$ & $56 \pm 8$ & $<.001$ \\
\hline $\mathrm{PIP}, \mathrm{cm} \mathrm{H}_{2} \mathrm{O}$ & $15 \pm 4$ & $18 \pm 4$ & $<.001$ \\
\hline Set PEEP, $\mathrm{cm} \mathrm{H}_{2} \mathrm{O}$ & $4 \pm 0.5$ & $4 \pm 0.5$ & $>.99$ \\
\hline Measured PEEP, $\mathrm{cm} \mathrm{H}_{2} \mathrm{O}$ & $5.1 \pm 0.5$ & $4.4 \pm 0.5$ & $<.001$ \\
\hline $\begin{array}{l}\Delta \text { pressure (PIP }- \text { measured } \\
\text { PEEP), } \mathrm{cm} \mathrm{H}_{2} \mathrm{O}\end{array}$ & $9.8 \pm 3.3$ & $13.5 \pm 3.9$ & $<.001$ \\
\hline Tidal volume, $\mathrm{mL} / \mathrm{kg}$ & $2.6 \pm 0.4$ & $4.6 \pm 0.8$ & $<.001$ \\
\hline Inspiratory time, $\mathrm{s}$ & $0.22 \pm 0.01$ & $0.31 \pm 0.02$ & $<.001$ \\
\hline Mean airway pressure, $\mathrm{cm} \mathrm{H}_{2} \mathrm{O}$ & $8.9 \pm 1.9$ & $8.4 \pm 1.6$ & .02 \\
\hline $\mathrm{F}_{\mathrm{IO}_{2}}$ & $52 \pm 14$ & $53 \pm 17$ & .96 \\
\hline $\mathrm{S}_{\mathrm{pO}_{2}}, \%$ & $93 \pm 1$ & $92 \pm 1$ & .39 \\
\hline $\mathrm{P}_{\mathrm{tcCO}_{2}}, \mathrm{~mm} \mathrm{Hg}$ & $53 \pm 6$ & $52 \pm 6$ & .31 \\
\hline Heart rate, beats/min & $157 \pm 7$ & $156 \pm 7$ & .64 \\
\hline Mean arterial pressure, $\mathrm{mm} \mathrm{Hg}$ & $37 \pm 5$ & $35 \pm 4$ & .10 \\
\hline
\end{tabular}

Data are presented as mean $\pm \mathrm{SD}$.

$\mathrm{P}_{\mathrm{tcCO}_{2}}=$ transcutaneously measured partial pressure of carbon dioxide

and none of the infants enrolled in the study developed air leaks.

\section{Discussion}

The results of this trial show that, in comparison with conventional ventilation, mid-frequency ventilation allowed the use of lower $\Delta$ pressures and tidal volumes while maintaining adequate gas exchange. PIP and tidal volume, the surrogate indicators of volutrauma and barotrauma, were lower during mid-frequency ventilation. Our results suggest that when fast frequencies are used, lower tidal volumes can provide adequate gas exchange in infants with RDS without hemodynamic impairment.

The application of the mid-frequency ventilation strategy has been tested in mathematical models, ${ }^{23}$ a highfidelity adult lung simulator, ${ }^{23}$ and acute lung injury animal models. ${ }^{24}$ The feasibility and efficacy of the mid-frequency ventilation strategy using an algorithm to adjust the ventilator parameters to achieve optimal frequency were evaluated in an acute lung injury piglet model. ${ }^{24}$ Although we incorporated the basic principles of mid-frequency ventilation, our study did not use this algorithm to achieve optimal ventilator frequency. We utilized flow-time graphics displayed on the ventilator monitor and the concept of time constant to reach the ventilator frequency. Hence, optimal frequency in this context was the frequency that minimized the tidal volume while still allowing zero flow crossing during inspiratory and expiratory times. We did not use a constant duty cycle but instead used set constant minimum inspiratory and expiratory times to achieve com- 
pleted flows. In contrast to the previous study, ${ }^{24}$ wherein decreased tidal volume was due to extremely short inspiratory time and decreased $\Delta$ pressure (partially from generated auto-PEEP), tidal volume was decreased in our study by adjusting PIP, targeting the same baseline level of gas exchange.

Conventional neonatal ventilators can operate at frequencies up to 150 breaths/min. However, a frequency of $<60$ breaths/min is usually used in clinical practice. ${ }^{28}$ The reasons for not operating conventional ventilators at higher than conventional frequencies may include progressive decrease in alveolar minute ventilation, ${ }^{20,21}$ auto-PEEP generation from gas trapping with subsequent overdistention of lungs, ${ }^{29,30}$ and decrease in the mean airway pressure if adequate bias flow is not maintained. ${ }^{21}$ Modern ventilators can achieve faster pressurization of the system as long as optimum inspiratory rise time is provided. ${ }^{31}$ The current study did not show impairment of gas exchange or hemodynamics even at faster frequencies and very low tidal volumes, consistent with clinical, ${ }^{32}$ animal, ${ }^{24}$ and experimental laboratory ${ }^{33}$ studies. We speculate that, although tidal volume was only slightly larger than the anatomical dead space, fast frequencies maintained adequate alveolar minute ventilation.

Improved short-term neonatal outcomes have been reported with the use of conventional ventilators operated at faster frequencies. Randomized control studies comparing rapid (60 breaths/min) versus slow (usually $30-40$ breaths/min) frequencies have reported reductions in air leaks (pneumothoraces and/or pulmonary interstitial emphysema) in preterm infants with RDS receiving positive-pressure ventilation with rapid frequencies. ${ }^{16,17}$ A meta-analysis of the 3 randomized studies showed a significant reduction in pulmonary air leaks and trend toward decrease in mortality with the use of positive-pressure ventilation with a faster rate..$^{15}$

Algorithm-based adjustments of ventilator settings, continuous monitoring of $\mathrm{P}_{\mathrm{tcCO}_{2}}$, and randomized crossover study designs are the main strengths of this feasibility study. The primary outcome variable, $\Delta$ pressure, which was determined by deducting measured PEEP from set PIP, serves as a reasonable surrogate for average tidal volume for all types of pressure ventilation modes. The small sample size and short duration are the main limitations of this study. Because this study was performed without using sedation and/or paralysis, an expiratory pause was not used to estimate the auto-PEEP because spontaneous breathing would have interfered with accurate estimation. Hence, total PEEP was not measured in this study; instead, measured PEEP was used as a surrogate for total PEEP. In the absence of esophageal pressure probes, measured PEEP estimation based on ventilator display might have underestimated the total PEEP generated during midfrequency ventilation. Because the pneumotachograph was not located at the patient end, poor correlation of expiratory tidal volume displayed on the ventilator with the actual expiratory tidal volume is another limitation of the study. ${ }^{34,35}$ The endotracheal clamping maneuver was not used to estimate the volume lost in the ventilator circuit, which might have overestimated the tidal volume measurement. The generalizability of the study may be limited because infants who were considered too unstable were excluded, and we included only infants with RDS who had a short time constant of the respiratory system and were thus likely to tolerate fast frequencies. Future trials of mid-frequency ventilation could include critically ill infants with RDS or other pulmonary conditions, and a longer intervention period should be tested, now that feasibility has been observed.

Several concerns need to be considered while using a mid-frequency ventilation strategy for neonatal ventilation for a longer duration. Since a short inspiratory time and very low tidal volume are being used, alveolar de-recruitment over the course of ventilation is a concern. ${ }^{36,37}$ Lower tidal volumes may not result in better neonatal respiratory outcomes because many randomized, controlled trials of high-frequency ventilation (which operates at smaller tidal volumes) have not shown consistent benefits over conventional ventilation. ${ }^{38}$ Applicability of a mid-frequency ventilation strategy to neonates with varying pulmonary mechanics and varying time constants is another concern because the present study evaluated feasibility only in preterm infants with surfactant-treated RDS. We speculate that optimal frequencies needed to ventilate infants with different lung mechanics would change based on the time constants. With increasing time constants, the proportionate increase in the inspiratory and expiratory times would require relatively lower ventilator rates to enable completed inspiratory flow and to avoid air trapping. Doubling the frequency from baseline has been reported to be associated with increased lung injury in rabbits while being ventilated with conventional ventilators with tidal volumes $>10 \mathrm{~mL} / \mathrm{kg} .{ }^{39}$ However, mid-frequency ventilation works on a completely different principle, whereby delivered tidal volumes are decreased at higher ventilator rates, and thus, as shown by a lung simulator study, ${ }^{23}$ overventilation and overdistention are possibly minimized. The potential suppression of spontaneous breathing efforts of neonates at higher ventilator frequency is another possible disadvantage of using mid-frequency ventilation. We believe that the primary advantage of the mid-frequency strategy over high-frequency ventilation is that special devices (such as high-frequency oscillators or jet ventilators) and special operating experiences (as needed while operating oscillators or jet ventilators) are not needed. Thus, a mid-frequency ventilation strategy has the potential to improve cost and convenience but needs to be tested in larger clinical trials before generalization. Whether mid-frequency 


\section{Mid-Frequency Ventilation in Neonates with RDS}

ventilation is better as primary ventilation or as rescue ventilation has not been determined, but mid-frequency may be superior to conventional ventilation, as suggested by the meta-analysis of the trials using a frequency of 60 breaths/min. Although the mid-frequency ventilation strategy appears safe and promising in this small feasibility trial, routine clinical application of this strategy for neonatal ventilation should not be considered until the efficacy and safety data are available from adequately powered, larger clinical trials.

\section{Conclusion}

This crossover randomized trial demonstrated the feasibility of mid-frequency ventilation in preterm infants by using conventional ventilators (Puritan Bennett 840 ventilators). The tidal volume, $\Delta$ pressure, and PIP requirements during the mid-frequency ventilation period were lower, whereas the same level of gas exchange as with conventional ventilation was achieved. Because the present study was a small feasibility trial with surrogate outcomes, a meaningful conclusion regarding the clinical importance of the results cannot be stated. Hence, midfrequency ventilation is a potential lung-protective ventilation strategy, but before considering this strategy for routine clinical application, it should be tested for a longer duration and in varied patient populations to determine effectiveness, safety, and generalizability.

\section{REFERENCES}

1. Roberts D, Dalziel S. Antenatal corticosteroids for accelerating fetal lung maturation for women at risk of preterm birth. Cochrane Database Syst Rev 2006;(3):CD004454.

2. Carlo WA, McDonald SA, Fanaroff AA, Vohr BR, Stoll BJ, Ehrenkranz RA, et al. Association of antenatal corticosteroids with mortality and neurodevelopmental outcomes among infants born at 22 to 25 weeks' gestation JAMA 2011;306(21):2348-2358.

3. Seger N, Soll R. Animal derived surfactant extract for treatment of respiratory distress syndrome. Cochrane Database Syst Rev 2009; (8):CD000144.

4. Rojas-Reyes MX, Morley CJ, Soll R. Prophylactic versus selective use of surfactant in preventing morbidity and mortality in preterm infants. Cochrane Database Syst Rev 2012;(3):CD000510.

5. Fischer HS, Bührer C. Avoiding endotracheal ventilation to prevent bronchopulmonary dysplasia: a meta-analysis. Pediatrics 2013; 132(5):e1351-e1360.

6. Yoder BA, Harrison M, Clark RH. Time-related changes in steroid use and bronchopulmonary dysplasia in preterm infants. Pediatrics 2009;124(2):673-679.

7. Stoll BJ, Hansen NI, Bell EF Shankaran S, Laptook AR, Walsh MC, et al. Trends in care practices, morbidity, and mortality of extremely preterm neonates, 1993-2012. JAMA 2015;314(10):1039-1051.

8. Shah PS, Sankaran K, Aziz K, Allen AC, Seshia M, Ohlsson A, et al. Outcomes of preterm infants $<29$ weeks gestation over 10-year period in Canada: a cause for concern? J Perinatol 2012;32(2):132-138.

9. SUPPORT Study Group of the Eunice Kennedy Shriver NICHD Neonatal Research Network. Early CPAP versus surfactant in extremely preterm infants. N Engl J Med 2010;362(21):1970-1979.
10. Soll RF, Edwards EM, Badger GJ, Kenny MJ, Morrow KA, Buzas JS, Horbar JD. Obstetric and neonatal care practices for infants 501 to $1500 \mathrm{~g}$ from 2000 to 2009. Pediatrics 2013;132(2):222-228.

11. LeVan JM, Brion LP, Wrage LA, Gantz MG, Wyckoff MH, Sánchez $\mathrm{PJ}$, et al. Change in practice after the surfactant, positive pressure and oxygenation randomised trial. Arch Dis Child Fetal Neonatal Ed 2014;99(5):F386-F390.

12. Jobe AH, Kramer BW, Moss TJ, Newnham JP, Ikegami M. Decreased indicators of lung injury with continuous positive expiratory pressure in preterm lambs. Pediatr Res 2002;52(3):387-392.

13. Bose CL, Dammann CE, Laughon MM. Bronchopulmonary dysplasia and inflammatory biomarkers in the premature neonate. Arch Dis Child Fetal Neonatal Ed 2008;93(6):F455-F461.

14. Wallace MJ, Probyn ME, Zahra VA, Crossley K, Cole TJ, Davis PG, et al. Early biomarkers and potential mediators of ventilation-induced lung injury in very preterm lambs. Respir Res 2009;10:19.

15. Greenough A, Dimitriou G, Prendergast M, Milner AD. Synchronized mechanical ventilation for respiratory support in newborn infants. Cochrane Database Syst Rev 2008;(9):CD000456.

16. Heicher DA, Kasting DS, Harrod JR. Prospective clinical comparison of two methods for mechanical ventilation of neonates: rapid rate and short inspiratory time versus slow rate and long inspiratory time. J Pediatr 1981;98(6):957-961.

17. Oxford Region Controlled Trial of Artificial Ventilation (OCTAVE) Study Group. Multicentre randomised controlled trial of high against low frequency positive pressure ventilation. Arch Dis Child 1991; 66(7 Spec No):770-775.

18. Pohlandt F, Saule H, Schröder H, Leonhardt A, Hörnchen H, Wolff $\mathrm{C}$, et al. Decreased incidence of extra-alveolar air leakage or death prior to air leakage in high versus low rate positive pressure ventilation: results of a randomised seven-centre trial in preterm infants. Eur J Pediatr 1992;151(12):904-909.

19. Greenough A, Greenall F, Gamsu H. Synchronous respiration: which ventilator rate is best? Acta Paediatr Scand 1987;76(5):713-718.

20. Boros SJ, Bing DR, Mammel MC, Hagen E, Gordon MJ. Using conventional infant ventilators at unconventional rates. Pediatrics 1984;74(4):487-492.

21. Greenough A, Greenall F. Performance of respirators at fast rates commonly used in neonatal intensive care units. Pediatr Pulmonol 1987;3(5):357-361.

22. Bland RD, Kim MH, Light MJ, Woodson JL. High frequency mechanical ventilation in severe hyaline membrane disease an alternative treatment? Crit Care Med 1980;8(5):275-280.

23. Mireles-Cabodevila E, Chatburn RL. Mid-frequency ventilation: unconventional use of conventional mechanical ventilation as a lungprotection strategy. Respir Care 2008;53(12):1669-1677.

24. Mireles-Cabodevila E, Chatburn RL, Thurman TL Zabala LM, Holt SJ, Swearingen CJ, Heulitt MJ. Application of mid-frequency ventilation in an animal model of lung injury: a pilot study. Respir Care 2014;59(11):1619-1627.

25. Chatburn RL, El-Khatib M, Mireles-Cabodevila E. A taxonomy for mechanical ventilation: 10 fundamental maxims. Respir Care 2014; 59(11):1747-1763.

26. Alegría X, Claure N, Wada Y, Esquer C, D’Ugard C, Bancalari E. Acute effects of PEEP on tidal volume and respiratory center output during synchronized ventilation in preterm infants. Pediatr Pulmonol 2006;41(8):759-764.

27. Ambalavanan N, Schelonka RL, Carlo WA. Assisted ventilation of the neonate, 5th edition. St Louis: Saunders-Elsevier; 2011:265-276.

28. van Kaam AH, Rimensberger PC, Borensztajn D, De Jaegere AP, Neovent Study Group. Ventilation practices in the neonatal intensive care unit: a cross-sectional study. J Pediatr 2010;157(5):767-771.e1-e3. 


\section{Mid-Frequency Ventilation in Neonates with RDS}

29. Cartwright DW, Willis MM, Gregory GA. Functional residual capacity and lung mechanics at different levels of mechanical ventilation. Crit Care Med 1984;12(5):422-427.

30. Hird M, Greenough A, Gamsu H. Gas trapping during high frequency positive pressure ventilation using conventional ventilators. Early Hum Dev 1990;22(1):51-56.

31. Donn SM. Neonatal ventilators: how do they differ? J Perinatol 2009;29(Suppl. 2):S73-S78.

32. Herrera CM, Gerhardt T, Claure N, Everett R, Musante G, Thomas C, Bancalari E. Effects of volume-guaranteed synchronized intermittent mandatory ventilation in preterm infants recovering from respiratory failure. Pediatrics 2002;110(3):529-533.

33. Keszler M, Montaner MB, Abubakar K. Effective ventilation at conventional rates with tidal volume below instrumental dead space: a bench study. Arch Dis Child Fetal Neonatal Ed 2012;97(3):F188-F192.

34. Cannon ML, Cornell J, Tripp-Hamel DS, Gentile MA, Hubble CL, Meliones JN, Cheifetz IM. Tidal volumes for ventilated infants should be determined with a pneumotachometer placed at the endotracheal tube. Am J Respir Crit Care Med 2000;162(6):2109-2112.
35. Chan MD, Heulitt MJ, Mireles-Cabodevila E, Thurman TL, Holt S. Use of airway sensor improves volume accuracy with mid-frequency ventilation. AJRCCM Conference 2011. doi: 10.1164/ajrccmconference.2011.183.1_MeetingAbstracts.A3382.

36. Lista G, Castoldi F, Fontana P, Reali R, Reggiani A, Bianchi S, Compagnoni G. Lung inflammation in preterm infants with respiratory distress syndrome: effects of ventilation with different tidal volumes. Pediatr Pulmonol 2006;41(4):357-363.

37. Marini JJ. Mid-frequency ventilation: a viable option for lung protection? Respir Care 2014;59(11):1808-1809.

38. Cools F, Henderson-Smart DJ, Offringa M, Askie LM. Elective high frequency oscillatory ventilation versus conventional ventilation for acute pulmonary dysfunction in preterm infants. Cochrane Database Syst Rev 2009;(3):CD000104.

39. Mittal RA, Simbruner G, Smith J, Simbruner B, Holzinger A. Mechanical ventilation with high tidal volume or frequency is associated with increased expression of nerve growth factor and its receptor in rabbit lungs. Pediatr Pulmonol 2009;44(7):713719 